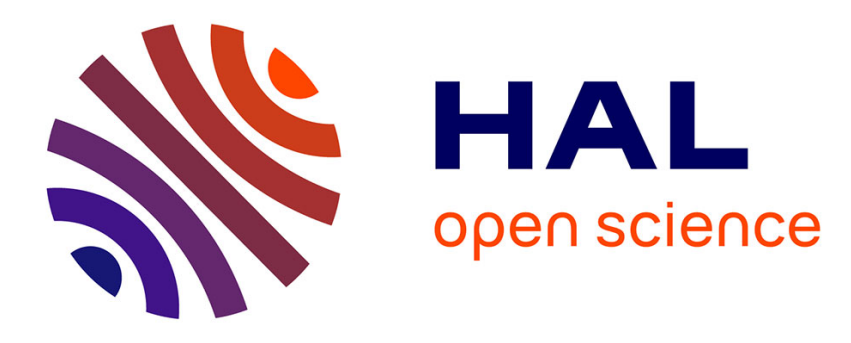

\title{
An Entropy-Based Approach for Measuring Complexity in Supply Chains
}

Filiz Isik

\section{To cite this version:}

Filiz Isik. An Entropy-Based Approach for Measuring Complexity in Supply Chains. International Journal of Production Research, 2010, 48 (12), pp.3681-3696. 10.1080/00207540902810593 . hal00583571

\section{HAL Id: hal-00583571 \\ https://hal.science/hal-00583571}

Submitted on 6 Apr 2011

HAL is a multi-disciplinary open access archive for the deposit and dissemination of scientific research documents, whether they are published or not. The documents may come from teaching and research institutions in France or abroad, or from public or private research centers.
L'archive ouverte pluridisciplinaire HAL, est destinée au dépôt et à la diffusion de documents scientifiques de niveau recherche, publiés ou non, émanant des établissements d'enseignement et de recherche français ou étrangers, des laboratoires publics ou privés. 


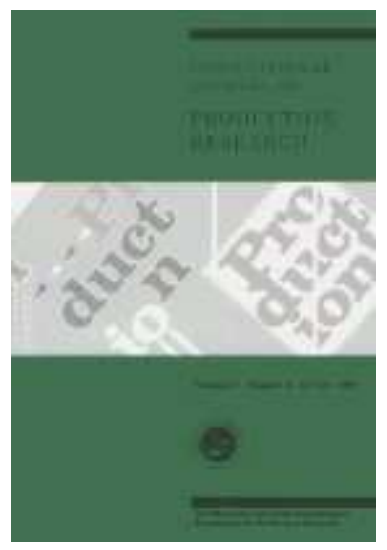

\section{An Entropy-Based Approach for Measuring Complexity in Supply Chains}

\begin{tabular}{|r|l|}
\hline Journal: & International Journal of Production Research \\
\hline Manuscript ID: & TPRS-2008-IJPR-0881.R1 \\
\hline Manuscript Type: & Original Manuscript \\
\hline $\begin{array}{r}\text { Date Submitted by the } \\
\text { Author: }\end{array}$ & 04-Feb-2009 \\
\hline Complete List of Authors: & $\begin{array}{l}\text { Isik, Filiz; University of Duisburg-Essen, Technology and Operations } \\
\text { Kanagement }\end{array}$ \\
\hline Keywords: & SUPPLY CHAIN DYNAMICS, SUPPLY CHAIN MANAGEMENT \\
\hline \multicolumn{2}{|c}{ SUPPLY CHAIN DYNAMICS, SUPPLY CHAIN MANAGEMENT } \\
\hline
\end{tabular}

\section{今 ScholarONE" \\ Manuscript Central}




\title{
An Entropy-Based Approach for Measuring Complexity in Supply Chains
}

\author{
Filiz Isik \\ Am Buchenbaum 37 \\ 47051 Duisburg \\ Germany \\ Tel. +491727477599 \\ E-Mail. filiz21376@yahoo.com
}

\begin{abstract}
Today's supply chains are more complex than ever due to globalization and its effects especially on the logistics activities. Therefore, understanding and managing complexity in supply chains are very popular topics nowadays. Measures for complexity in supply chains contribute to their manageability and controllability. This paper describes an approach to the measurement of complexity in supply chains based on the Shannon's information entropy. The new proposed approach gives a formal approach that is able to measure and analyze the supply chain complexity. The main contribution of this study is to extend two formulas (structural and operational complexity) building on the Shannon's entropy measure to evaluate the complexity of a supply chain. The aim is to measure complexity associated with information and material flows in the chain. A numerical example is presented to demonstrate the approach.
\end{abstract}

Key words: Complexity, Supply Chain, Entropy, Measurement.

\section{Introduction}

Competitiveness is essential for every company in the business world. Every company wants to reduce their costs to compete better. Globalization, customers' expectations, reduced costs, shorter allowed lead-times, shorter product life cycles, etc. are parameters that determine business success.

To compete successfully, companies are using mergers, acquisitions, and joint ventures to achieve market penetration, product launches to combat the rise in commoditization, and outsourcing to keep costs low, while improving service levels to meet the growing expectations of customers. As a result, supply chains are growing increasingly complex (Vickers and Kodarin 2006). Successful businesses are now those able to master this evolution. So, after exploiting all internal resources, companies have started to focus more closely on their supply chain, seeking an overall cost reduction and an overall increase of effectiveness and efficiency. Therefore, improving competitiveness of a company now involves suppliers and distributors thus making the overall system more complex. As a matter of fact, many managers are realizing that the control of this overall complexity is a strategic issue for the company, and for the whole supply chain (Perona and Miragliotta 2004).

However complexity in supply chains is defined, a high or low complexity comprises no value itself. Low or high complexity in supply chains might include both advantages and disadvantages. On one hand, complexity can sometimes be necessary and value adding. For 
example, it could help a company to gain market share. On the other hand, low complexity does not necessarily need to be positive but might be expensive for the company.

Complexity may enable flexibility. High complexity includes advantages when the customer pays for it that means when the market is demanding a lot of variety. For example, mass customization involves deliberately expanding the complexity of the product range to offer customers greater variety. The key is to be able to do this without raising prices. This is the balance of a successful mass customization strategy. A manufacturer can have a lot of complexity in stock. If suppliers are variable and unpredictable or customers keep changing their minds at the last minute, then, the manufacturer can accommodate it by keeping stock. It is how a manufacturer often deals with it and is therefore a symptom of high complexity but, of course the manufacturer is then paying for the storage. High complexity includes disadvantages when a facility is not operating well and generating a lot of information which a manufacturer must pay for that high complexity merely involves additional cost (Frizelle and Efstathiou 2002). Therefore, complexity is very difficult to manage. In order to manage complexity better, it is first recommended to be measured so that it can be understood how big it is both in absolute and relative terms. The present paper focuses on defining and measuring supply chain complexity. A measure based on the entropy method will be derived and discussed. It has been first introduced in manufacturing by Frizelle and Woodcock (1995). This paper discusses their approach and expands it according to some drawbacks presented in the discussion.

Complexity measures as discussed in this paper, based on entropy, have many useful advantages and can be simply applied in the industrial world. They are also relevant in supply chains to examine the performance of a supply chain's interfaces between the manufacturer, the supplier and the customer. Supply chains can be analyzed by this method from many perspectives. It can be used in order to compare the flows (material and information), different products on different product lines, supply chain partners, etc. The entropy measure presented here can also be used for analyzing internal, external and total complexity of a supply chain business partner.

\section{Literature Review}

Complexity as a concept is widely discussed in several scientific areas such as physics, biology, chemistry, mathematics, computer science and economics. This paper focuses on supply chain complexity (SCC). From the theoretical perspective, some researchers studied complexity in manufacturing. Wilding (1998) described the interaction between deterministic chaos, parallel interactions and demand amplification as a "supply chain complexity triangle" in order to understand the generation of uncertainty within supply chains. Calinescu et al. (2001) classified complexity in manufacturing into three categories: decision-making complexity, structural complexity and behavioural complexity to analyze the manufacturing complexity. Milgate (2001) described the dimensions of supply chain complexity as uncertainty, technological intricacy and organizational system to manage it. To manage complexity in manufacturing, understanding and measuring complexity is becoming increasingly important. This paper focuses on the measurement of the supply chain complexity associated with uncertainty and variety. One of the approaches to evaluate uncertainty is the information-theoretic entropy-based measure, which was first introduced by Shannon in 1948. Although the concept of entropy is known as a measure of thermodynamic, it has been used also as statistical measure in manufacturing. From the statistical perspective, some authors applied the entropy-based measure to manufacturing. Yao (1985) studied the entropy as a measure of flexibility. Deshmukh et al. (1992) and Deshmukh et al. (1998) 
provided a static measure of complexity based on entropy method. Ronen and Karp (1994) developed an approach which includes a formula for determining the location of a lot based on entropy measurement. Johnston (1996) studied the production flexibility and the market complexity based on entropy measure.

The academic work of entropy-based measures in supply chains has been first elaborated by the Institute for Manufacturing (IFM) at Oxford and Cambridge Universities. The aim of the IFM research was to define and to quantify the complexity in supply chains (Frizelle and Woodcock 1995; Calinescu et al. 1998; Sivadasan et al. 2002; Sivadasan et al. 2006). Frizelle and Woodcock (1995) defined an entropy-based measure to quantify complexity in supply chains based on Shannon's information entropy. They classified complexity into structural (static) and operational (dynamic). Structural complexity deals with variety (schedule) and operational complexity deals with uncertainty (deviation from the schedule). In their work, supply chain is considered as a random variable with different states and corresponding probabilities for each state.

The new proposed approach gives a formal approach that is able to measure and to analyze the supply chain complexity. The main contribution of this study is to develop two new measures for structural and operational complexity building on Frizelle and Woodcock (1995) approach by using Shannon's information entropy (Shannon, 1948). In Shannon's (1948) and Frizelle's and Woodcock's (1995) work, complexity is only a function of probabilities of different states. This paper argues that complexity is not only a function of probabilities of different states, but also each state can have different complexity level of its own that needs to be considered. As a contribution of the new approach, an expected value is defined for each state, and the deviation from that expected value is measured. In order to demonstrate the new approach, a numerical example is presented and the complexity measures (structural and operational) of a supply chain system are calculated using these new proposed formulas.

\section{Complexity and its Dimensions}

Understanding and measuring complexity become increasingly important in manufacturing, especially in supply chains. It is difficult to define what complexity really means. There are many definitions of complexity in literature. Some of them are

- Complexity is being marked by an involvement of many parts, aspects, details, notions, and necessitating earnest study or examination to understand or cope with (Webster's Third International Dictionary, Gove 1986).

- Complexity arises from not only the size of the system but also from the interrelationships of the system components and the emergent behaviour that cannot be predicted from the individual system components (Arteta and Giachetti 2004).

Regarding these definitions and referring to the goal of this study, complexity here is seen as the quantitative differences between two states (predicted and real) which include uncertainty and/or variety and associated with internal and external causes in a (supply chain) system.

Obviously, uncertainty and variety are not the only dimensions (factors) which have influence on complexity. There are also other dimensions of complexity. According to Reiss 
(1993), four significant dimensions can be identified that drive complexity: namely size (number), diversity, variety and uncertainty.

Size (Number) includes e.g. number of products, processes, partners, customers, goals, locations, etc. The higher the number of the systems ' component, the higher the complexity. This way of measuring complexity is relatively easy to capture because it is not surprising to know that, if the number is reduced, complexity will also be reduced. Therefore, if the number of the parameter under consideration is changed, complexity of the system also changes.

Diversity covers the homogeneity or heterogeneity of the system. The more heterogeneous (or less homogeneous) the system is, the higher (the lower) the complexity is.

Variety (variability) is associated with the variations of internal and external states (environment), requirements, and sources in the course of time. If the types of the system elements change rapidly or unexpectedly, the complexity of the system increases. This component of complexity integrates the dynamic aspects of complexity.

Uncertainty comprises the difficulties to make a clear picture of the system. Indefiniteness, risks, ambiguities, ambivalences are some examples of a systems` deficit and cause uncertainty. If uncertainty increases, complexity will increase as well.

Measuring complexity is not only a value for itself but is a tool to evaluate a company's status with respect to complexity and must be in line with the company goals as well as must substantiate these goals. In this paper, I will focus on the uncertainty and variety aspects of SCC. Size (number) and diversity will not be addressed explicitly here.

\section{Supply Chain Complexity}

A complex system is a system with numerous components and interconnections, interactions, or interdependencies that are difficult to describe, understand, predict, manage, design, and/or change (Magee and de Weck 2002: Engineering Systems Division, MIT 2002). Complex systems are typically organizations made of many heterogeneous parts interacting locally in the absence of a centralized pacemaker and control (Fontana and Ballati 1999). Several factors contribute to system complexity: (i) the number of components in the system, (ii) the number of relationships among these components (i.e., the degree of coupling), and (iii) the types of relationships between the components (Gonzalez et al. 2005). As a system a supply chain is also complex and the business environment is uncertain. The supply chain is a complex network of facilities and organizations with different, conflicting objectives. This implies that finding the best supply chain strategy for a particular firm poses significant challenges (Simchi-Levi and Kaminsky 2000).

The variety and uncertainty of a supply chain might be extremely high and cause complexity. It can be associated with organizational, operational or technical causes of a supply chain. The more uncertainty or variety in a system, the more complex the supply network. A typical supply chain can often be complex, due to the following (Blackhurst 2004):

- Large mesh of interlinked participants (information and material flows) including suppliers, manufacturers and distributors across multiple organizations.

- Each of these participants may be a member of a large number of other supply chains. 
- Dynamic and uncertain nature of the supply chain.

- Each participant may have differing objectives.

Based on the theory-oriented literature (such as Frizelle and Woodcock 1995; Calinescu et al. 2001; Sivadasan et al. 2002; Blackhurst 2004 etc.) SCC can be defined as all operational uncertainties and/or structural varieties associated with internal or external causes by the information and/or material flows along the supply chain that are known, unknown, expected, unexpected, predicted or unpredicted.

A supply chain is a system with multiple business partners who work somehow independently of each other. Each supply chain participant has its own complexity level which can have impact on the other participants. A small complexity level of one participant in the chain can have a large impact on the whole supply chain system. For example, in a simple supply chain system which includes a single supplier, manufacturer and costumer (see figure 1) when demand forecast (schedule production) of the manufacturer has some deviation from the actual order (sales orders) from its customer, it can result in massive changes of manufacturer demand (purchasing orders) to its supplier. Variation of orders can increase up the supply chain from customer to supplier. This effect is also known as the "bullwhip effect" in the supply chain literature.

Within a supply chain, material and information flows represent the main complexity drivers because of uncertainty and/or variety in this study. The reasons causing complexity can originate from inside or from outside of a supply chain system. Therefore, complexity in a supply chain can be classified generally into three main categories, namely as internal SCC, external SCC and total SCC. Each business partner can have its own internal, external and total complexity level in a chain.

Internal Supply Chain Complexity is associated with material and information flows within a business partner of a supply chain. Internal SCC depends on the structure of the single business partner. Examples for increased SCC are: process deficits, material shortness, machine breakdowns, bad management techniques, large product variety, etc.

External Supply Chain Complexity is associated with material and information flows exported by other business partners to a partner. The causes might be related to globalization, technological innovation, customer demand variety, etc.

Total Supply Chain Complexity is associated with material and information flows within a business partner as well as amongst its other business partners. It includes both internal and external complexity.

Figure 1: Complexity Flows in a Supply Chain

A coarse diagram of the complexity flows in a supply chain between manufacturer and its business partners (supplier and customer) are shown in figure 1. In this diagram internal SCC is associated with flows within the manufacturer; external SCC is associated with flows from a supplier and/or from a customer to the manufacturer and vice versa and total complexity covers all internal and external complexity.

\section{Entropy as a Measure of Complexity}


A supply chain is a complex system and before companies cope with it, they should first define "how complex this system is". But this is a general context. If we want to define the complexity of a system or compare two systems (A and B), to be able to say that system A is more complex than system B, we need some sort of quantitative indicator. Therefore, the Shannon's entropy is used to measure complexity quantitatively in this paper because it is simple and most widely used in uncertainty measure of a system in the relevant literature. Unfortunately, there are not many complexity measures which can be applied in manufacturing systems. Kolmogorov`s entropy (Kolmogorov 1965) or Reny`s entropy can be used as a measure of uncertainty as well and they will be studied in the future work.

Although the entropy is known as a physical concept in the thermodynamic system and was first introduced by Rudolf Julius Emmanuel Clausius (1822-1888), later on scientists studied it from statistical aspect (such as Ludwig Eduard Boltzmann (1844-1906), James Clerk Maxwell (1831-1879), Claude Elwood Shannon, (1916-2001)). Of the different entropy measures, Shannon's entropy (Shannon 1948) is the most popular and common one and has established its usefulness in almost every area of science and technology, economics etc. (Mandal and Pal 2003).

It is well known that "Shannon entropy measures the average uncertainty (in bits) associated with the prediction of outcomes in a random experiment" (Klir and Yuan 1995). The basic idea behind the measure is that occurrence of events that have high probability provides less information (uncertainty) than occurrence of events that have low probability. The average uncertainty associated with an outcome is represented by discrete random variable X. The Shannon's information entropy (Shannon 1948) of a discrete random variable $\mathrm{X}$, with $n$ outcomes $\left(x_{1}, \ldots, x_{n}\right)$ is:

$$
H(X)=-\sum_{i=1}^{n} p\left(x_{i}\right) \log _{2} p\left(x_{i}\right)
$$

where $p\left(x_{i}\right)$ is the probability of outcomes of a system being in state $i,(i=1, \ldots, n)$, $p\left(x_{i}\right) \geq 0, \sum_{i=1}^{n} p\left(x_{i}\right)=1$ and $\log _{2}(0)=0$.

Shannon used logarithm to the base 2 in the entropy formula to give entropy the dimension of a binary digit (bit) which represents an answer, such as "0" or "1," "yes" or "no," or "on" or "off". In certain cases, it is possible to give a numerical measure to the amount of information (in the Shannon sense) in a state, which can tell us little about what the system is doing. The definition of a system state is often only an abbreviation of the essential information needed to characterize the system, as indicated in the dictionary definitions (Reeker and Jones 2002). In complexity measurement, a state is defined as a description of the target (order), the resources, a recipe, and constraints (Meijer 2002). A system can have one or many states at a point of observation.

The entropic complexity measure (Shannon's information entropy) is only a function of probabilities of different states. But each state can have different entropy/complexity level of its own that needs to be considered. It means each state can have its own expected outcome value in a system. The expected value needs to be defined with respect to the problems that are being addressed. The complexity in this paper is defined as variation between expected and actual flows. The existence of variation between planned and actual flows shows that 
there is a complexity. If the variation between flows is zero there is not any complexity occurring. It is often expected that there is not any variation between the flows. In other words there is not any deviation from the schedule. Therefore, the expected outcome value for this study is zero. However, the expected value can also be some tolerated variation between expected and actual flows in a supply chain system according to the company and its structure. The corresponding deviation from that expected value shows the complexity of that particular state. Therefore, the equation (2) is proposed as a measure of entropy/complexity that includes the deviation value $\left(d_{i}\right)$ from the expected value.

The main contribution of the paper is modification of equation (1) as follows:

$H^{I}=-\sum_{i=1}^{n}\left[\log _{2} p_{i}\right] p_{i} d_{i}$

where $d_{i}$ is the deviation of outcomes $\left(x_{1}, \ldots, x_{n}\right)$ from the expected outcome value for the state. The value of $d_{i}$ can be negative, zero or positive. Permitting negative values for $d_{i}$ makes equation (2) almost useless as a measure of entropy because a large negative value can change it drastically (robustness issue). Due to that reason absolute value of $d_{i}$ will be considered as the deviation of an outcome from its expected outcome in the formulas.

\section{Measuring Supply Chain Complexity based on Entropy Method}

The entropy based complexity measure for supply chains was first introduced by Frizelle and Woodcock (1995) and has been successfully used in industry (Sivadasan et al. 2002). Their work includes a mathematical model that provides a measure for structural (static) complexity by equation (3) and operational (dynamic) complexity by equation (4). Furthermore they have defined operational complexity as complexity index in their study and applied their approach also to some companies (EPSRC, Unilever, BAE Systems and AEA Technology), (see http://www-mmd.eng.cam.ac.uk/complexity).

Structural (static) complexity, arising from the impact the product structure has on the resources that will produce it and represents the expected amount of information required to define the state of the system for a given period, is based on the information in the schedule (Frizelle and Woodcock 1995; Calinescu et al. 1998). Structural complexity can be written (Frizelle and Woodcock 1995):

$$
H^{I}(s)=-\sum_{i=1}^{M} \sum_{j=1}^{N} p_{i j} \log _{2} p_{i j}
$$

where

$H^{I}(s) \quad$ : Structural complexity

$p_{i j} \quad$ : Probability of resource $i, i=1, \ldots, M$ being in state $j, j=1, \ldots, N$ 
$M \quad$ : Number of resources

$N \quad$ : Number of possible states for resource $i$

Operational (dynamic) complexity determines the operational behavior from direct observation of the process, in particular on how queues behave (in terms of queue length, variability and compositions) and represents the amount of information required to define the state of the system, based on monitoring the system for a given period. Operational complexity is related to the monitoring of planned and unplanned events (Calinescu et al. 2000). Operational complexity can be defined as (Frizelle and Woodcock 1995):

$$
H^{I}{ }_{(o)}=-(1-P) \sum_{i=1}^{M} \sum_{j=1}^{N} p_{i j} \log _{2} p_{i j}
$$

where

$H^{I}{ }_{(0)}$ : Operational complexity (Complexity Index)

$P \quad$ : Probability of the system being "in control (scheduled)" state

$(1-P)$ : Probability of the system being "out of control (unscheduled)" state

Complexity can be associated with information or material flows within a supply chain. The information complexity measurements are recorded by sampling the variability in the primary information flows associated with forecast accuracy and schedule adherence. The material flow complexity is measured by sampling variations associated with schedule reliability of delivery and dispatch and variability of stock (Frizelle and Woodcock 1995; Sivadasan et al. 1999). For the complexity measurement scheduled (in control) and unscheduled (out of control) are defined as possible states of a supply chain in this study. Regarding this definition each supply chain flow (information/material) has its own in control and out of control states which have to be considered. Table 1 shows some possible complexity measure variations in quantities associated with supply chain flows. They will not be addressed in this paper.

\begin{tabular}{|c|l|}
\hline $\begin{array}{c}\text { Complexity by Supply Chain Flows } \\
\text { (Information / Material) }\end{array}$ & \multicolumn{1}{c|}{ Measure Variations } \\
\hline \multirow{2}{*}{ Information } & Requested Delivery - Confirmed Delivery \\
\cline { 2 - 2 } & Confirmed Delivery - Forecast Delivery \\
\cline { 2 - 2 } & Confirmed Delivery - Provisional Delivery \\
\cline { 2 - 2 } & Scheduled Delivery - Forecast Delivery \\
\hline
\end{tabular}


The modified structural complexity can be defined:

$$
H_{(s)}^{I I}=-\sum_{i=1}^{M} \sum_{j=1}^{N}\left[\log _{2} p_{i j}\right] d_{i j} p_{i j}
$$

The modified operational complexity can be defined:

$$
H^{I I}{ }_{(o)}=-(1-P) \sum_{i=1}^{M} \sum_{j=1}^{N}\left[\log _{2} p_{i j}\right] d_{i j} p_{i j}
$$

\section{Numerical Example}

The differences between predicted (forecasted) and real situations are "out of control" states in the chain and defined as complexity in this example. Complexity arises from the material and information flows exchanged between supply chain partners. Forecast and actual orders between a customer and its supplier are created, e. g. every month as a simple example 
to show how to use the complexity measure (see table 2). The supplier-costumer system is illustrated in figure 2 .

Figure 2: Supplier-Costumer System

In order to illustrate the variations between forecast and actual order (from table 2) better, the two curves are plotted in figure 3.

Figure 3: Graphic of Forecast and Actual Order (Example)

Table 2: Sample Data Collection for Expected and Actual Flows

The quantitative differences between planned and actual value of monthly order are used as the outcome data $X$ (discrete random variable) with 25 outcomes $\left(x_{1}, \ldots, x_{25}\right)$. In this case the discrete random variable is classified into two states, "in control" and "out of control". The in control states include planned or scheduled states and the out of control states include unplanned or unscheduled states. The system is said to be "in control", if the quantitative differences between expected and actual flows equal zero, and if not, the system is said to be "out of control". Therefore, the expected outcome value for this example is zero. The state definitions are illustrated in table 3.

Table 3: The State Definition

The next step is to compute the differences between expected and actual order quantities. Expected values are subtracted from actual values to define the differences (see also Sivadasan et al., 2002). All positive or negative differences between these two values are defined to be "out of control". A probability histogram of the data is created to analyse the complexity by indices. The differences are categorized within the chosen ranges. The ranges can be generally defined depending on the problem structure that is being addressed. In this example " $+6 \leq \mathrm{x} \leq+10$ ", " $+1 \leq \mathrm{x} \leq+5$ ", " $-5 \leq \mathrm{x} \leq-1$ " and " $-10 \leq \mathrm{x} \leq-6$ " are chosen as ranges (see table 4). After that, frequencies for each ranges and the probability of these frequencies are determined. Structural complexity is calculated by using equation (3). In order to define the structural complexity, all complexity values are added up (see structural complexity column in table 4). The probabilities that represent the "in control" state $(P)$ are used to define operational complexity (complexity index) by equation (4). The system is "in control" if the complexity is zero. System states which are "in control" reduce the complexity of the whole system. Therefore, equation (3) is modified by multiplying the factor $(1-P)$ with the sum of the weighted probability values of the "out of control" states which yields equation (4). 
If the results of table 2 are analyzed according to state effects, it can be observed that there is a weakness. I. e. two different ranges (for example the ranges " $+6 \leq x \leq+13$ " and " -5 $\leq \mathrm{x} \leq-1$ ") could have the same complexity value (0.46) because of the same probability value, but cannot have the same distance to the expected value (table 4). Obviously from a practical point of view, the larger the distance to the expected value the greater the complexity of the system will be. Therefore two additional formulas (equations (5) and (6)) are proposed including distance to expected value for structural and operational complexity measures. In this way, the more realistic result seems to be obtained as compared with the classical entropy measurement: While keeping basically the "under control" and "out of control" approaches of entropy, the different distances of states being "not under control" to the "under control" situation are explicitly included into the measures. Thus measures (5) and (6) allow also to measure relative improvements of a system, even if the portion of (truly) under control situations does not change but the "amount" of being out of control has reduced nevertheless. I. e. mathematically, the formulas have an additional parameter to cover the deviation value from the expected value. The mid-range of the each histogram cells are used as outcome $d_{i j}$ (deviation from the expected value for the state) for equations (5) and (6). In order to demonstrate the new proposed approach, the complexity measures of the customer-supply system, both structural and operational, are calculated using equations (5) and (6) and it is shown in table 5 .

Table 5: Calculation of Structural and Operational Complexity according to classical and new complexity measures

The results in table 5 show that there are structural complexity of values 1.87 and 11.37 and complexity indices of 1.57 and 9.55 between expected and actual orders. I. e. there is a difference between classical and new structural complexity values because the distances from the expected value are not taken into consideration by the classical complexity measure. This argument can be explained by an example: The frequency value of the range " $-5 \leq \mathrm{x} \leq-$ 1 " is exchanged with the value of " $-13 \leq \mathrm{x} \leq-6$ " and complexity values are calculated again. Table 6 shows the results.

According to the classical measure the complexity value (1.87) remains unchanged although the frequency values are exchanged. But according to the new measure the complexity value changes because of the " $d_{i j}$ " effect. Therefore the new approach is proposed to obtain more meaningful results as compared with the classical approach. The classical complexity measure is able to indicate the controllability of the system, i. e. whether the system is ,under control "or not. But it seems to be even more important to know how big the complexity, i. e. the 'amount of non-controllability', is. Therefore I propose the above measure to overcome the pure binary approach of 'under control' and 'out of control' by explicitly including a component into the complexity measure which maps a state's 'degree of being out of control'. 
Table 6: Calculation of Structural and Operational Complexity according to Frequency Exchange

Also from a cost perspective of complexity, the modified approach proposed here might be advantageous: If a state's distance from being under control has an influence on the complexity costs (e. g. higher penalty costs if a manufacturer is not able to deliver ordered products in time) then this should be regarded in the complexity evaluation of a system. Supposing no difference with respect to two states' frequency, the state with the further distance to the under control situation should be ceteris paribus considered first for complexity reduction approaches.

\section{Conclusions and Future Work}

Supply chains and supply chain management are important topics in the globalized world during the recent years. Therefore, analysis, measurement and reduction techniques of the increasing complexity of supply chains play an important economic role. In this paper the uncertainty of supply chain were measured based on the entropy method from a viewpoint of classical (Shannon's entropy measure) and new proposed approaches. The goal of this study is to give a formal approach which is able to measure the influence of the entropy measure on SCC environment. The results of the study seem to be interesting and meaningful. Shannon's entropy measure is used because it is simple and most widely used in uncertainty measurement. Of course, it is not the only measure for uncertainty or complexity respectively. Some other measurement methods could be studied in the future as well (such as Lyapunov exponent or fuzzy set theory).

The study presents a binary approach for classical measurement of complexity in supply chains. The classical entropy measure of SCC focuses whether the system is "under control" or "out of control". If the differences between actual and expected flow equal zero then the system is said to be "under control" and if not the system is "out of control". This study proposes a somehow different approach with respect to this aspect. It concentrates on predictability of a system and compares two models which are "more under control" than others. The system which has higher complexity (indicated by complexity index) should ceteris paribus be considered first with respect to complexity reduction as compared to the system with low complexity index. The more divergence to an expected value the greater the complexity. Therefore two additional formulas were developed that have an additional parameter to cover the range effect. While reducing complexity, the situations that are very far from situations of "under control" should be considered first and, if possible, reduced as compared with situations that are nearly "under control". The proposed new measure is in line with this view on complexity.

The classical entropy-based complexity measures, which are presented here, have been successfully applied and refined in industry by Sivadasan et al. (2002). However, regarding new proposed measures complexity will be also applied in industry in order to highlight its use in practice. Further research should be directed to more empirical work on the new proposed complexity measure in more detail.

Complexity can be associated with demand distortion up to supply chain from supplier to manufacturer. This effect is known as bullwhip effect in the literature. The new proposed entropy-based complexity measure can be used as a bullwhip measure as well. The future work will be concentrated on entropic complexity measure as a bullwhip metric. 


\section{References}

Arteta, B.M., and Giachetti, R.E., (2004). A measure of agility as the complexity of the enterprise system. Journal of Robotics and Computer-Integrated Manufacturing. 20 (6), 495503.

Blackhurst, J., Wu, T., and O'Grady, P., (2004), Network-based approach to modeling uncertainty in a supply chain, International Journal of Production Research, 42 (8), 16391658.

Calinescu, A., Efstathiou, J., Schim, J., and Bermejo, J., (1998), Applying and assessing two methods for measuring complexity in manufacturing, Journal of the Operational Research Society, 49 (7), 723-733.

Calinescu, A., Efstathiou, J., Sivadasan, S., Schirn, J., and Huaccho Huatuco, L., (2000), "Complexity in Manufacturing: An Information Theoretic Approach", in: McCarthy I. P. and Rakotobe-Joel T. (Eds.), Proceedings of the Conference on Complexity and Complex Systems in Industry. The University of Warwick, Warwick, pp. 30-44.

Calinescu, A., Efstathiou, J., Huatuco, L.H., and Sivadasan, S., (2001), Classes of complexity in manufacturing, paper presented at The 17th National Conference on Manufacturing Research, University of Cardiff, 4-6 September.

Deshmukh, A. V., Talavage, J. J., and Barash, M. M., (1992), Characteristics of Part Mix Complexity Measure for Manufacturing systems, IEEE International Conference on Systems, Man and Cybernetics, New York, USA, pp 1384-1389.

Deshmukh, A. V., Talavage, J. J., and Barash, M. M., (1998), Complexity in manufacturing systems, Part 1: Analysis of static complexity, IIE Transactions, 30 (7), 645-655.

Fontana, W., and Ballati, S., (1999), Complexity: an essay, Complexity, 4 (3), 14-16.

Frizelle, G., and Woodcock, E., (1995), Measuring complexity as an aid to developing operational strategy, International Journal of Operations and Production Management, 15 (5), 26-39.

Frizelle, G., and Efstathiou, J., (2002), Seminar Notes On "Measuring Complex Systems". Available from: http://www.psych.lse.ac.uk/complexity/events/2002/GerjanApril02lastversion.pdf

Gonzalez, C., Vanyukov, P., and Martin, M., (2005), The use of microworlds to study dynamic decision making, Computers in Human Behavior, 21 (2), 273-286.

Gove, P. B., (1986), Complexity, Webster's third new international dictionary of the English language unabridged", Merriam-Webster-Verlag.

Johnston, R. B., (1996), From Efficiency to Flexibility: Entropic Measures of Market Complexity and Production Flexibility, Complexity International, Vol. 3. 
Klir, G. J., and Yuan, B., (1995), Fuzzy Sets and Fuzzy Logic: Theory and Applications, Prentice-Hall, Englewood Cliffs.

Kolmogorov, A., (1965), Three approaches to the quantitative definition of information, Problems of Information Transmission,.2 (1-4), 157-168.

Magee, C. L., and de Weck, O. L., (2002), “An attempt at complex system classification”, ESD Internal Symposium, MIT 2002. Available from:

http://esd.mit.edu/WPS/ESD Internal Symposium Docs/ESD-WP-2003-01.02-ESD Internal Symposium.pdf (Magee, de Weck 2002)

Mandal, D. P., and Pal, N. R., (2003), On the utility of different entropy measures in image thresholding, In: Karmeshu, Ed. Entropy Measures, Maximum Entropy Principle and Emerging Applications. New York: Springer-Verlag, pp 177-198.

Meijer, B. R., 2002, Reducing Complexity through Organizational Structuring in Manufacturing and Engineering. Manufacturing Complexity Network Conference, Cambridge (UK), Available from:

http://www.ifm.eng.cam.ac.uk/mon/pdf files/part6 2.pdf

Milgate, M., (2001), Supply chain complexity and delivery performance: an international exploratory study, Supply Chain Management: an international Journal, 6 (3), 106-118.

Perona, M., and Miragliotta, G., (2004), Complexity management and supply chain performance assessment: a field study and a conceptual framework, International Journal of Production Economics, 90 (1), 103-115.

Reeker, L. H. and Jones, A. T., (2002), A New Classification of Information: A Step on the Road to Interpretability, Nist Special Publication Sp, 990, 349-358. Available from:

http://www.isd.mel.nist.gov/research_areas/research_engineering/Performance_Metrics/PerM IS 2002 Proceedings/Reeker_Jones.pdf

Reiss, M., (1993), Komplexitätsmanagement (I) Working Paper, Stuttgart, pp. 54-59.

Ronen, B., and Karp, R., (1994), An information entropy approach to the small-lot concept, IEEE Transactions on Engineering Management, 41 (1), 89-92.

Shannon, C. E., (1948), The Mathematical Theory of Communication, The Bell System technical Journal, 27, 379-423.

Simchi-Levi, D., Kaminsky, P., (2000), Designing and managing the supply chain: concepts, strategies and case studies, Simchi-Levi, D., Ed. Singapore: McGraw-Hill International Edition.

Sivadasan, S., Efstathiou, J., Shirazi, R., Alves, J., Frizelle, G., Calinescu, A., (1999), Information Complexity as a Determining Factor in the Evolution of the Supply Chain, Proceedings of International Workshop on Emergent Synthesis, $6^{\text {th }}-7^{\text {th }}$ December 1999, Kobe University, Japan, pp. 237-242.

Sivadasan, S., Efstathiou, J., Frizelle, G., Shirazi, R., and Calinescu, A., (2002), An information-theoretic methodology for measuring the operational complexity of supplier- 

80-102.

Sivadasan, S., Efstathiou, J., Calinescu, A., and Huatuco, L. H., (2006), Advances on measuring the operational complexity of supplier-customer systems, European Journal of Operational Research, 171 (1), 208-226.

Vickers, P., and Kodarin, A., (2006), Deriving Benefit from Supply Chain Complexity, PRTM, White Paper. Available from:

(http://www.supplychainstandard.com/assets/getAsset.aspx?liAssetID=173)

Wilding, R., (1998), The supply chain complexity triangle: Uncertainty generation in the supply chain, International Journal of Physical Distribution and Logistics Management, 28 (8), 599-616.

Yao, D. D., (1985), Material and information flows in flexible manufacturing systems, Material Flow, 2, 143-149. 


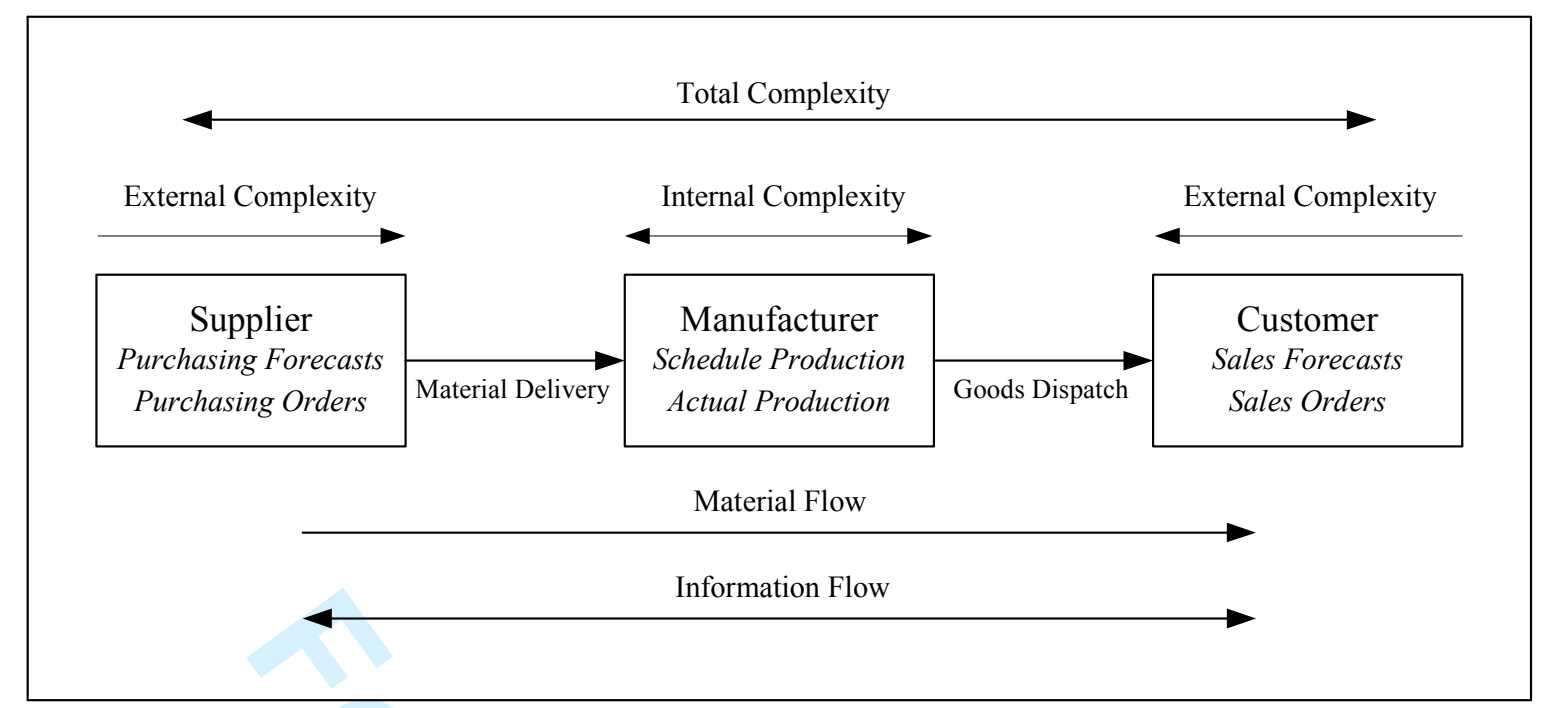

Figure 1: Complexity Flows in a Supply Chain

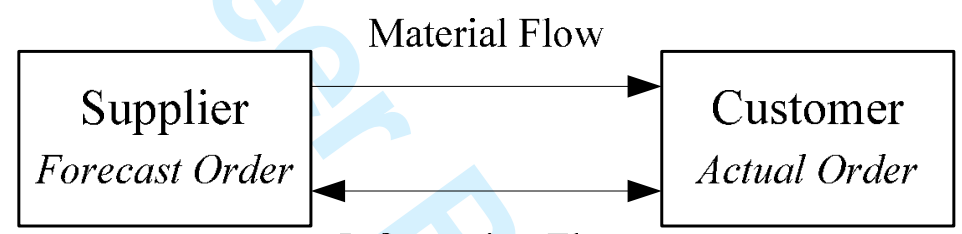

Information Flow

Figure 2: Supplier-Costumer System

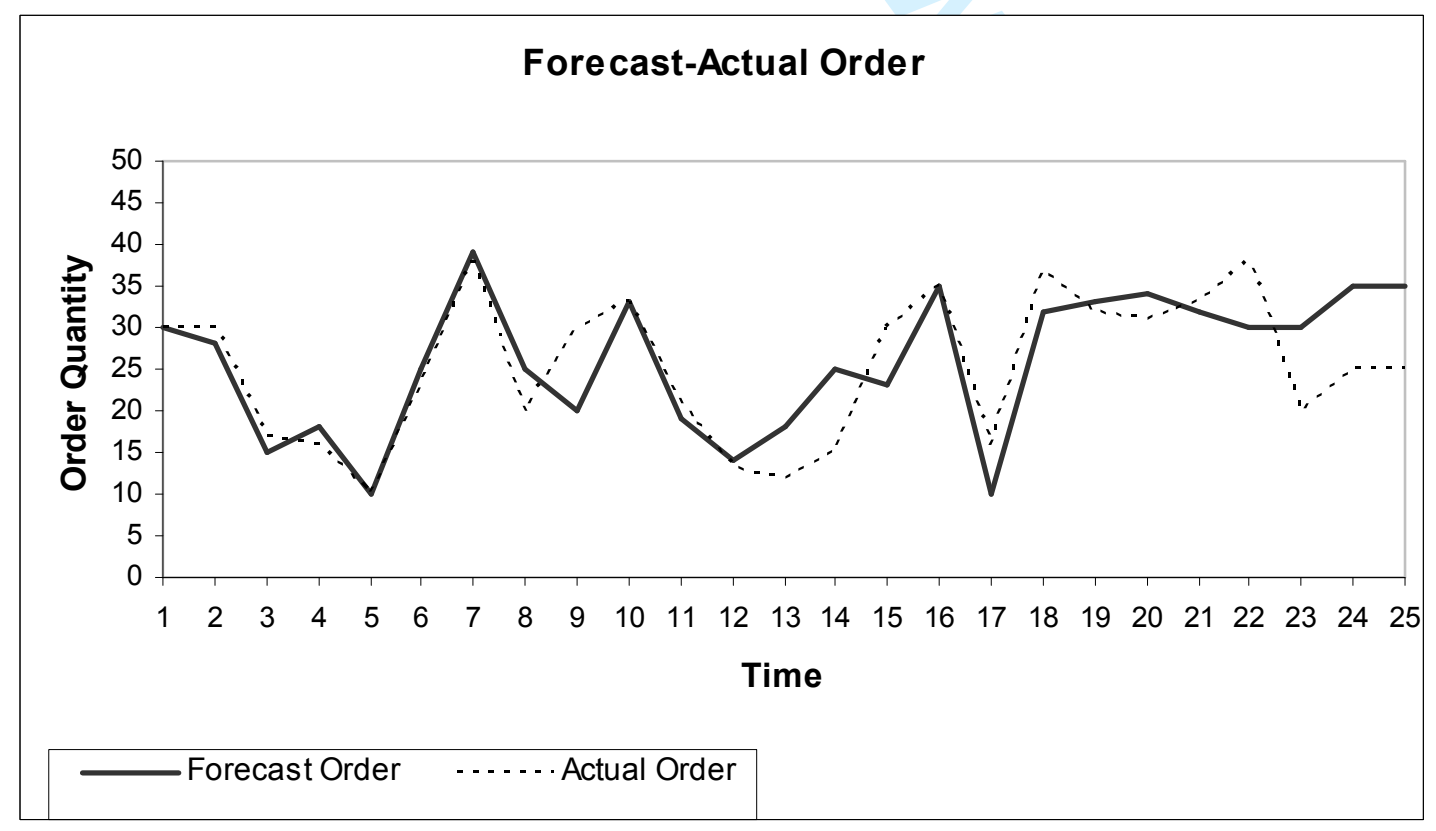

Figure 3: Graphic of Forecast and Actual Order (Example) 
1

2

3

\section{Complexity by Supply Chain Flows \\ (Information / Material)}

\begin{tabular}{|l|l|}
\hline \multirow{4}{*}{ Information } & Requested Delivery - Confirmed Delivery \\
\cline { 2 - 2 } & Confirmed Delivery - Forecast Delivery \\
\cline { 2 - 2 } & Confirmed Delivery - Provisional Delivery \\
\cline { 2 - 2 } & Scheduled Delivery - Forecast Delivery \\
\cline { 2 - 2 } & Scheduled Delivery - Confirmed Delivery \\
\hline \multirow{3}{*}{ Material } & Actual Production - Scheduled Production \\
\cline { 2 - 2 } & Actual Delivery - Scheduled Delivery \\
\cline { 2 - 2 } & Actual Dispatch - Scheduled Dispatch \\
\hline
\end{tabular}

Table 1: Some Possible Complexity Measure Variations by Supply Chain Flows (adopted from Sivadasan et al. 1999)

\begin{tabular}{|c|c|c|c|}
\hline $\begin{array}{l}\text { Time } \\
\text { (Months) }\end{array}$ & $\begin{array}{l}\text { Forecast Order } \\
\text { (Expected Flow) }\end{array}$ & $\begin{array}{l}\text { Actual Order } \\
\text { (Actual Flow) }\end{array}$ & $\begin{array}{c}\text { Variation } \\
\text { (Expected - Actual) }\end{array}$ \\
\hline 0 & 30 & 30 & 0 \\
\hline 1 & 28 & 30 & -2 \\
\hline 2 & 15 & 17 & -2 \\
\hline 3 & 18 & 2 & 2 \\
\hline 4 & 10 & 10 & 0 \\
\hline 5 & 25 & 2 & 2 \\
\hline 6 & 39 & 38 & 1 \\
\hline 7 & 25 & 20 & 5 \\
\hline 8 & 20 & 30 & -10 \\
\hline 9 & 33 & 33 & 0 \\
\hline 10 & 19 & 21 & -2 \\
\hline 11 & 14 & 13 & 1 \\
\hline 12 & 18 & 12 & 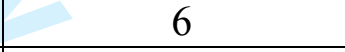 \\
\hline 13 & 25 & 15 & 10 \\
\hline 14 & 23 & 30 & -7 \\
\hline 15 & 35 & 35 & 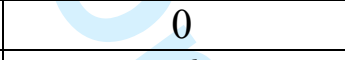 \\
\hline 16 & 10 & 16 & -6 \\
\hline 17 & 32 & 37 & -5 \\
\hline 18 & 33 & 32 & 1 \\
\hline 19 & 34 & 31 & 3 \\
\hline 20 & 32 & 33 & -1 \\
\hline 21 & 30 & 38 & -8 \\
\hline 22 & 30 & 20 & 10 \\
\hline 23 & 35 & 25 & 10 \\
\hline 24 & 35 & 25 & 10 \\
\hline
\end{tabular}

Table 2: Sample Data Collection for Expected and Actual Flows 


\begin{tabular}{|c|c|l|}
\hline State & $\begin{array}{c}\text { Quantitative Differences } \\
\text { (Forecast - Actual Order) }\end{array}$ & \multicolumn{1}{c|}{ Definition } \\
\hline $\begin{array}{c}\text { "in control" } \\
\text { / scheduled }\end{array}$ & $=0$ & $\begin{array}{l}\text { No variation between the expected } \\
\text { and actual flows }\end{array}$ \\
\hline $\begin{array}{c}\text { "out of control"/ } \\
\text { non scheduled }\end{array}$ & $>0$ or $<0$ & $\begin{array}{l}\text { Positive or negative variations, } \\
\text { which must be taken under control }\end{array}$ \\
\hline
\end{tabular}

Table 3: The State Definition

\begin{tabular}{|c|c|c|c|c|}
\hline \multirow{4}{*}{ State Range } & & & & Complexity/Entropy \\
& Range & Frequency & Probability & $H_{(s)}^{I}=-\sum_{i=1}^{M} \sum_{j=1}^{N} p_{i j} \log _{2} p_{i j}$ \\
& & & & \\
\hline In Control & 0 & & & 0,16 \\
\hline \multirow{3}{*}{ Out of Control } & $+6 \leq \mathrm{x} \leq+13$ & 5 & 0,20 & 0,46 \\
\cline { 2 - 5 } & & & 0,28 & 0,51 \\
\cline { 2 - 5 } & $-5 \leq \mathrm{x} \leq-1$ & 5 & 0,20 & 0,46 \\
\cline { 2 - 5 } & $-13 \leq \mathrm{x} \leq-6$ & 4 & 0,16 & 0,42 \\
\hline Structural Complexity & & & 1,87 \\
\hline
\end{tabular}

Table 4: Calculation of Structural and Operational Complexity

\begin{tabular}{|l|c|c|c|c|}
\hline \multirow{2}{*}{ State Range } & \multicolumn{2}{|c|}{ Forecast -Actual Order } \\
\cline { 3 - 5 } & \multirow{2}{*}{ Frequency } & Probability & $H_{(s)}^{I}=-\sum_{i=1}^{M} \sum_{j=1}^{N} p_{i j} \log _{2} p_{i j}$ & $H^{I I}(s)=-\sum_{i=1}^{M} \sum_{j=1}^{N}\left[\log _{2} p_{i j}\right]_{i j} p$ \\
\cline { 3 - 5 } & & & $($ Classical) & $(\mathrm{New})$ \\
\hline 0 (in control) & 4 & 0,16 & 0 & 0 \\
\hline$+6 \leq \mathrm{x} \leq+13$ & 5 & 0,20 & 0,46 & 4,41 \\
\hline$+1 \leq \mathrm{x} \leq+5$ & 7 & 0,28 & 0,51 & 1,54 \\
\hline$-5 \leq \mathrm{x} \leq-1$ & 5 & 0,20 & 0,46 & 1,39 \\
\hline$-13 \leq \mathrm{x} \leq-6$ & 4 & 0,16 & 0,42 & 11,02 \\
\hline Structural Complexity & & 1,87 & $\mathbf{9 , 5 5}$ \\
\hline $\begin{array}{l}\text { Operational Complexity } \\
\text { (Complexity Index) }\end{array}$ & & $\mathbf{1 , 5 7}$ & \\
\hline
\end{tabular}

Table 5: Calculation of Structural and Operational Complexity according to classical and new complexity measures 


\section{Forecast -Actual Order}

\begin{tabular}{|c|c|c|c|c|}
\hline \multirow{2}{*}{ State Range } & \multirow[b]{2}{*}{ Frequency } & \multirow[b]{2}{*}{ Probability } & \multicolumn{2}{|c|}{ Complexity/Entropy } \\
\hline & & & $\begin{aligned} H^{I}{ }_{(s)}= & -\sum_{i=1}^{M} \sum_{j=1}^{N} p_{i j} \log _{2} p_{i j} \\
& \text { (Classical) }\end{aligned}$ & $\begin{array}{c}H^{I I}{ }_{(s)}=-\sum_{i=1}^{M} \sum_{j=1}^{N}\left[\log _{2} p_{i j}\right] d_{i j} p_{i j} \\
\text { (New) }\end{array}$ \\
\hline 0 (in control) & 4 & 0,16 & 0 & $\begin{array}{c}0 \\
\end{array}$ \\
\hline$+6 \leq x \leq+13$ & 5 & 0,20 & 0,46 & 4,41 \\
\hline$+1 \leq \mathrm{x} \leq+5$ & 7 & 0,28 & 0,51 & 1,54 \\
\hline$-5 \leq x \leq-1$ & 4 & 0,16 & 0,42 & 1,27 \\
\hline$-13 \leq x \leq-6$ & 5 & 0,20 & 0,46 & 4,41 \\
\hline \multicolumn{3}{|c|}{ Structural Complexity } & 1,87 & 11,64 \\
\hline \multicolumn{3}{|c|}{$\begin{array}{l}\text { Operational Complexity } \\
\text { (Complexity Index) }\end{array}$} & 1,57 & 9,77 \\
\hline
\end{tabular}

Table 6: Calculation of Structural and Operational Complexity according to Frequency - Exchange 